Kansas State University Libraries

New Prairie Press

\title{
EVALUATING THE EFFECTS OF MONENSIN OVERDOSE IN DAIRY CATTLE
}

\author{
Rebecca R. Hozak \\ James T. Symanowski \\ David G. McClary \\ Meliton N. Novilla \\ John C. Kube
}

See next page for additional authors

Follow this and additional works at: https://newprairiepress.org/agstatconference

Part of the Agriculture Commons, and the Applied Statistics Commons

\section{(c) (i) $\ominus$}

This work is licensed under a Creative Commons Attribution-Noncommercial-No Derivative Works 4.0 License.

\section{Recommended Citation}

Hozak, Rebecca R.; Symanowski, James T.; McClary, David G.; Novilla, Meliton N.; Kube, John C.; McGuffey, R. Ken; Wilkinson, John I. D.; Green, Howard B.; and Thomas, Elvin E. (2005). "EVALUATING THE EFFECTS OF MONENSIN OVERDOSE IN DAIRY CATTLE," Conference on Applied Statistics in Agriculture. https://doi.org/10.4148/2475-7772.1139

This is brought to you for free and open access by the Conferences at New Prairie Press. It has been accepted for inclusion in Conference on Applied Statistics in Agriculture by an authorized administrator of New Prairie Press. For more information, please contact cads@k-state.edu. 


\section{Author Information}

Rebecca R. Hozak, James T. Symanowski, David G. McClary, Meliton N. Novilla, John C. Kube, R. Ken McGuffey, John I. D. Wilkinson, Howard B. Green, and Elvin E. Thomas 


\title{
EVALUATING THE EFFECTS OF MONENSIN OVERDOSE IN DAIRY CATTLE
}

\author{
Rebecca R. Hozak ${ }^{1}$, James T. Symanowski ${ }^{1}$, David G. McClary ${ }^{2}$, Meliton N. Novilla ${ }^{2,3}$, John C. \\ $\mathrm{Kube}^{2}$, R. Ken McGuffey ${ }^{2,3}$, John I. D. Wilkinson ${ }^{2}$, Howard B. Green ${ }^{2}$, Elvin E. Thomas ${ }^{2}$ \\ ${ }^{1}$ Global Statistics and Information Sciences \\ ${ }^{2}$ Elanco Animal Health \\ ${ }^{3}$ Retired \\ Eli Lilly and Company, 2001 W. Main St., Greenfield, IN 46140
}

\begin{abstract}
Monensin is approved as a feed additive by the FDA Center for Veterinary Medicine to increase milk production efficiency in lactating dairy cattle. To assess the effects of a gross error in mixing monensin into cattle feed, a 10-fold overdose was given for three consecutive days to naïve cows as well as cows previously dosed with monensin within the label range. Cows were evaluated during the overdose and for a subsequent 4 week observation period. Physiological variables were analyzed, including dry matter intake, body weight, body condition score, and serum chemistry profile. Production variables were analyzed, including milk yield and milk composition. Cows were blocked according to pre-treatment milk output, days in milk, and body condition. Results were analyzed using linear mixed model methodology with a baseline covariate. The study provided information for the veterinarian and the dairy farmer for determining whether an overdose may have occurred, for assessing the prognosis, and for deciding whether to continue feeding monensin immediately following an overdose.
\end{abstract}

\section{INTRODUCTION}

The overdose study was designed to examine the effects of a monensin overdose which might occur on a farm. Since monensin is provided to dairy cattle in their feed, an overdose could result from a mixing error. One of the goals of the study was to determine what signs the veterinarian and the farmer should expect if an overdose does occur. If there was another cause for health problems in a herd, this information could also help to rule out an overdose, and enable the veterinarians and farmers to identify the true problem more quickly. A second goal was to determine whether there was any difference in the recovery from an overdose between animals previously acclimated to monensin and naïve animals. Another goal was to assess whether it is better, after an overdose, to continue feeding the cows monensin (at the intended dose) or feed them unmedicated feed, and to determine if that answer depends on whether the animal was on monensin prior to the overdose.

\section{STUDY DESIGN}

The overdose study was conducted at the Elanco facilities in Greenfield, Indiana. The study included 22 multiparous cows in the second, third, or fourth lactation. Animals in the study were previously on an inclusion study to test for effects of sudden inclusion of monensin 
into diets during lactation. During the inclusion study, half of the animals were fed monensin at $24 \mathrm{ppm}$ (the high end of the approved dose range) and the other half received no monensin. By scheduling the overdose study immediately follow the inclusion study, the effects of an overdose on cows currently on monensin treatment and also on naïve cows could be determined.

During the overdose, all cows received 240 ppm monensin (a 10-fold overdose of the high end of the approved dose range) in their feed. Following the overdose, half of the cows in each of the inclusion dose groups were given $24 \mathrm{ppm}$ monensin and half were given no monensin. This allocation resulted in a factorial treatment design (Table 1) with the two levels of Inclusion Dose (0 and $24 \mathrm{ppm})$ crossed with the two levels of Recovery Dose (0 and $24 \mathrm{ppm})$.

A randomized complete block design was used, with blocking based on milk yield, days in milk (number of days into the lactation), and body condition score, at the beginning of the inclusion study. There were 5 complete blocks in which each of the Inclusion Dose by Recovery Dose combinations was represented, and one block with only two cows and two of the combinations represented. The cows were grouped into blocks such that all cows within a block had relatively similar levels for all of these variables, with milk yield handled as the most important of these factors.

\section{DATA COLLECTED}

Physiological and production variables were collected for analyses. The measurements were taken at various frequencies. Dry Matter Intake was measured daily. Body Condition Score, Body Weight, and Blood Chemistry were each measured at several specific timepoints throughout the study. Milk yield was measured daily, and milk composition was assessed 3 times per week. Only a subset of the data is presented here.

\section{DATA ANALYSIS AND RESULTS}

The study was divided into three phases for analysis. The first phase was the Overdose, which lasted for 3 days. The second phase was the Acute Recovery phase, defined as the 4 days following the overdose, and the third phase was the Chronic Recovery phase, defined as the subsequent 3-week period.

\subsection{Overdose}

During the three-day Overdose phase, all cows received the same dosage of monensin. The treatment difference analyzed for this phase was that half of the cows were previously dosed with monensin and half of the cows were unexposed. Therefore, the treatment effect that was being assessed during the Overdose phase was a treatment applied prior to the overdose.

The statistical model for the Overdose phase is given in Equation 1. A linear mixed model analysis was performed using $\mathrm{SAS} \otimes$ Proc Mixed. Baseline values, collected for the variables during the week prior to the overdose, were used as covariates. The covariate and the dose ( 0 or $24 \mathrm{ppm}$ monensin) given in the inclusion study were fixed effects in all models. The effects involving day (Day and the Dose*Day interaction) were included for those variables measured at multiple timepoints during the Overdose phase. Random effects included Block, Inclusion Dose by Block Interaction (since there were two cows per treatment group per complete block during the Overdose phase), and for those variables measured at multiple timepoints, Cow(Block). Standard normality assumptions were made regarding all random 
effects. Specifically, the levels of each random effect are independent identically-distributed normal random variables with a zero mean, and each random effect is independent of the others. The random effects created a compound symmetry covariance structure for analysis of variables measured at multiple timepoints. Because the error terms were linear combinations of variance components, the denominator degrees of freedom were calculated using the Satterthwaite approximation (1).

$$
\begin{aligned}
& Y_{i j k l}=\mu+\lambda\left(X_{i}-\bar{X}\right)+\alpha_{j}+\delta_{k}+\alpha \delta_{j k}+B_{l}+\alpha B_{j l}+c_{i}\left(B_{l}\right)+\varepsilon_{i j k l} \\
& Y_{i j k l}=\text { response value }
\end{aligned}
$$

\begin{tabular}{ll}
\multicolumn{2}{l}{ Fixed effects } \\
\hline$\mu$ & overall mean \\
$\lambda$ & Baseline coefficient ( $X_{i}=$ baseline measurement $)$ \\
$\alpha_{j}$ & Inclusion Dose \\
$\delta_{k}$ & Day \\
$\alpha \delta_{j k}$ & Inclusion Dose*Day
\end{tabular}

\section{$\underline{\text { Random effects }}$}

$B_{l} \quad$ Block

$\alpha B_{j l} \quad$ Inclusion Dose*Block

$c_{i}\left(B_{l}\right) \operatorname{Cow}($ Block $)$

$\varepsilon_{i j k l} \quad$ Residual Error

An alpha level of 0.05 was used for all statistical tests. The 0 and $24 \mathrm{ppm}$ monensin Inclusion Dose treatment groups were compared across the entire Overdose phase. For variables where multiple measurements were collected during the phase, the Day and Dose by Day interaction were assessed over the entire phase. Additionally, for those variables where multiple measurements were collected, linear contrasts comparing doses were presented at each timepoint, regardless of overall significant differences. For example,

$$
H_{\circ}: \mu_{A t}-\mu_{B t}=0 \quad \text { vs. } \quad H_{\mathrm{A}}: \mu_{A t}-\mu_{B t} \neq 0
$$

where $\mathrm{t}=$ indicates a given timepoint, $\mathrm{A}$ and $\mathrm{B}$ indicate Inclusion Dose treatment groups, and $\mu$ is the cell mean for the indicated treatment group and time. Although numerous response variables were analyzed and several tests calculated for most of the variables, no multiple comparison adjustments were used, since this was a safety study and it was important to identify all possible effects.

The baseline covariate was included in the model to adjust for between-animal variation. Additionally, since animals were previously on different treatments, there were substantial pre- 
existing differences between treatment groups in some of the variables to be measured. Normally, one would collect the covariate measurements prior to administering treatment. However, in this study, the interest was in assessing the differential change following an overdose between cows previously treated with monensin and cows which were unexposed. That is, the goal was to determine how the response variables changed for one group of cows following the overdose, compared to the other group of cows.

The daily dry matter intake (DMI) raw means are shown in Figure 1, plotted by the Inclusion Dose over the entire study, beginning with the baseline period. The Overdose phase is bracketed by vertical lines. This graph demonstrates the first sign of the overdose, which was a dramatic decrease in feed intake within 24 hours. The feed intake continued to decrease during the three day Overdose phase. The animals in the $0 \mathrm{ppm}$ Inclusion Dose group had slightly higher DMI before the overdose, but were more severely impacted by the overdose, with their intake dropping below that of the 24 ppm Inclusion Dose group animals.

The statistical analysis of the DMI for the Overdose phase is shown in Table 2. The overall effect from the Inclusion Dose was significant $(\mathrm{P}=0.008)$, as was the effect of Day $(\mathrm{P}<0.001)$. The baseline-adjusted least squares means show that the immediate drop in DMI was less severe for cows previously acclimated to monensin $(\mathrm{P}=0.003$ and 0.012 for Day 1 and Day 2 , respectively). However, by Day 3 of the overdose, DMI values were not different between the two groups $(\mathrm{P}=0.692)$.

\subsection{Recovery}

The data from the Acute Recovery phase (the four days following the overdose) and the Chronic Recovery phase (the subsequent three weeks) were analyzed separately. The analyses for Acute Recovery used daily response values, whereas the analyses for Chronic Recovery used weekly averages.

The analyses for both Recovery phases implemented the same statistical model, shown in Equation 3. Fixed effects included a baseline covariate, Inclusion Dose, Recovery Dose, and the interaction. For those variables measured at multiple timepoints, the effect for time (either Day or Week) and the related interactions were also included. Random effects were Block, and for those variables measured at multiple timepoints, Cow(Block). There were no interaction terms for the Dose effects with Block since there was only one cow per treatment combination in each block during Recovery. Standard normality assumptions were made regarding all random effects. Specifically, the levels of each random effect are independent identically-distributed normal random variables with a zero mean, and each random effect is independent of the others. The random effects created a compound symmetry covariance structure for analysis of variables measured at multiple timepoints. Because the error terms were linear combinations of variance components, the denominator degrees of freedom were calculated using the Satterthwaite approximation (1).

$$
\begin{gathered}
Y_{i j k l m}=\mu+\lambda\left(X_{i}-\bar{X}\right)+\alpha_{j}+\beta_{k}+\alpha \beta_{j k}+\tau_{l}+\alpha \tau_{j l}+\beta \tau_{k l}+\alpha \beta \tau_{j k l}+B_{m}+c_{i}\left(B_{m}\right)+\varepsilon_{i j k l m} \\
Y_{i j k l m}=\text { response value }
\end{gathered}
$$




\section{Fixed effects}

\begin{tabular}{ll}
\hline$\mu$ & overall mean \\
$\lambda$ & Baseline coefficient $\left(X_{i}=\right.$ baseline measurement $)$ \\
$\alpha_{j}$ & Inclusion Dose \\
$\beta_{k}$ & Recovery Dose \\
$\alpha \beta_{j k}$ & Inclusion Dose*Recovery Dose \\
$\tau_{l}$ & Time \\
$\alpha \tau_{j l}$ & Inclusion Dose*Time \\
$\beta \tau_{k l}$ & Recovery Dose*Time \\
$\alpha \beta \tau_{j k l}$ & Inclusion Dose*Recovery Dose*Time
\end{tabular}

\section{$\underline{\text { Random effects }}$}

$B_{m} \quad$ Block

$C_{i}\left(B_{m}\right) \operatorname{Cow}($ Block $)$

$\varepsilon_{i j k m} \quad$ residual error

An alpha level of 0.05 was used for all statistical tests. The dose effects were analyzed across each phase. For variables where multiple measurements were collected, the Time and Dose by Time interaction effects were assessed across the phase. Linear contrasts comparing dose main effects and interactions were also tested at each timepoint, for those variables. For example,

$$
\begin{array}{llll}
\text { Inclusion Dose Effect } & H_{\circ}: \bar{\mu}_{A \bullet t}-\bar{\mu}_{B \bullet t}=0 & \text { vs. } & H_{\mathrm{A}}: \bar{\mu}_{A \bullet t}-\bar{\mu}_{B \bullet t} \neq 0 \\
\text { Recovery Dose Effect } & H_{\circ}: \bar{\mu}_{\bullet A t}-\bar{\mu}_{\bullet B t}=0 & \text { vs. } \quad H_{\mathrm{A}}: \bar{\mu}_{\bullet A t}-\bar{\mu}_{\bullet B t} \neq 0
\end{array}
$$

Inclusion by Recovery Dose Effect

$$
\begin{aligned}
& H_{\circ}:\left(\mu_{A A t}-\mu_{B A t}\right)-\left(\mu_{A B t}-\mu_{B B t}\right)=0 \quad \text { vs. } \\
& H_{A}:\left(\mu_{A A t}-\mu_{B A t}\right)-\left(\mu_{A B t}-\mu_{B B t}\right) \neq 0
\end{aligned}
$$

where $\mathrm{t}=$ indicates a given timepoint, $\mathrm{A}$ and $\mathrm{B}$ indicate treatment groups for the Inclusion Dose [in the first subscript position] or for the Recovery Dose [in the second subscript position], and $\mu$ is the cell mean and $\bar{\mu}$ is the marginal mean for the indicated treatment group and time.

For DMI during the Acute Recovery phase, no interaction was detected in the overall tests (p-values $\geq 0.263$, Table 3 ). However, the Inclusion Dose and Day were both significant ( $p$ values $<0.001)$ and there was weak evidence $(\mathrm{P}=0.109)$ for a Recovery Dose effect. Contrasts for individual days showed that the Inclusion Dose effect was significant ( $p$-values $\leq 0.001$ ) for all four days. The least squares means showed that the baseline-adjusted DMI for the monensin- 
acclimated cows (24 ppm Inclusion Dose) continued to be higher than those of the naïve cows throughout the Acute Recovery phase. The Recovery Dose effect was not significant in the daily contrasts ( $p$-values $\geq 0.077$ ).

For DMI during the Chronic Recovery phase, there were no significant interactions in the overall tests ( $p$-values $\geq 0.349$, Table 4 ). The Inclusion Dose effect and the Week effect were significant ( $\mathrm{P}=0.009$ and $\mathrm{P}=0.028$, respectively), but the Recovery dose had little impact $(\mathrm{P}=0.727)$. Contrasts indicate Inclusion Dose differences exist by week during Weeks 2 and 3 Relative to Overdose ( $\mathrm{P}=0.012$ and $\mathrm{P}=0.015$, respectively). As shown by the least squares means for the Inclusion Dose, the cows previously acclimated to monensin had higher baseline-adjusted DMI than naïve cows.

As with DMI, the Recovery Dose had little impact on most response variables tested. However, in a few cases such as the milk fat percent during the Acute Recovery phase, the Recovery Dose effect was significant $(\mathrm{P}=0.030$, Table 5). Although the milk fat percent dropped following the overdose, the cows which were fed monensin after the overdose had less of a drop than those cows which were fed unmedicated feed. Additionally, the cows which were acclimated to monensin before the overdose had higher baseline-adjusted milk fat percent than naïve animals $(\mathrm{P}=0.011)$.

\section{SUMMARY}

The first alteration observed following the monensin overdose in lactating dairy cows was a reduction in dry matter intake by over $25 \%$ the first day. By the third day of the overdose, the cows were eating only approximately half of their pre-overdose feed amounts. Such a dramatic reduction in feed intake would indicate to a veterinarian or farmer that an overdose may have occurred.

Cows previously acclimated to monensin did not have as dramatic or rapid a decrease in dry matter intake during the overdose as did the naïve cows. The monensin-acclimated cows also recovered from the overdose more quickly. Similarly, monensin-acclimated cows experienced lesser effects from the overdose for many of the other physiological and production variables tested. Feeding the cows 0 vs 24 ppm monensin following the overdose had little impact on dry matter intake or most of the other response variables analyzed.

\section{ACKNOWLEDGMENTS}

The authors thank Rob Dennison for transferring the statistical results into tables and Andy Sponsler for generating the graph in Figure 1. We also thank Wherly Hoffman, Dan Mowrey, Alan Zimmermann, and the reviewer for helpful comments on the manuscript.

\section{REFERENCE}

1. Satterthwaite, F.E. 1946. An Approximate Distribution of Estimates of Variance Components, Biometrics Bulletin, 2, 110-114. 
Table 1. Treatment Design

\begin{tabular}{|c|c|c|c|}
\hline \multicolumn{3}{|c|}{ Monensin Dose (ppm) in Feed } & \multirow{2}{*}{$\begin{array}{c}\text { Number of } \\
\text { Cows }\end{array}$} \\
\hline $\begin{array}{c}\text { Inclusion } \\
28 \text { days }\end{array}$ & $\begin{array}{c}\text { Overdose } \\
3 \text { days }\end{array}$ & $\begin{array}{c}\text { Recovery } \\
25 \text { days }\end{array}$ & 6 \\
\hline 0 & 240 & 0 & 5 \\
\hline 0 & 240 & 24 & 5 \\
\hline 24 & 240 & 0 & 6 \\
\hline 24 & 240 & 24 & \\
\hline
\end{tabular}

Figure 1. Daily Dry Matter Intake Raw Means by Inclusion Dose Group

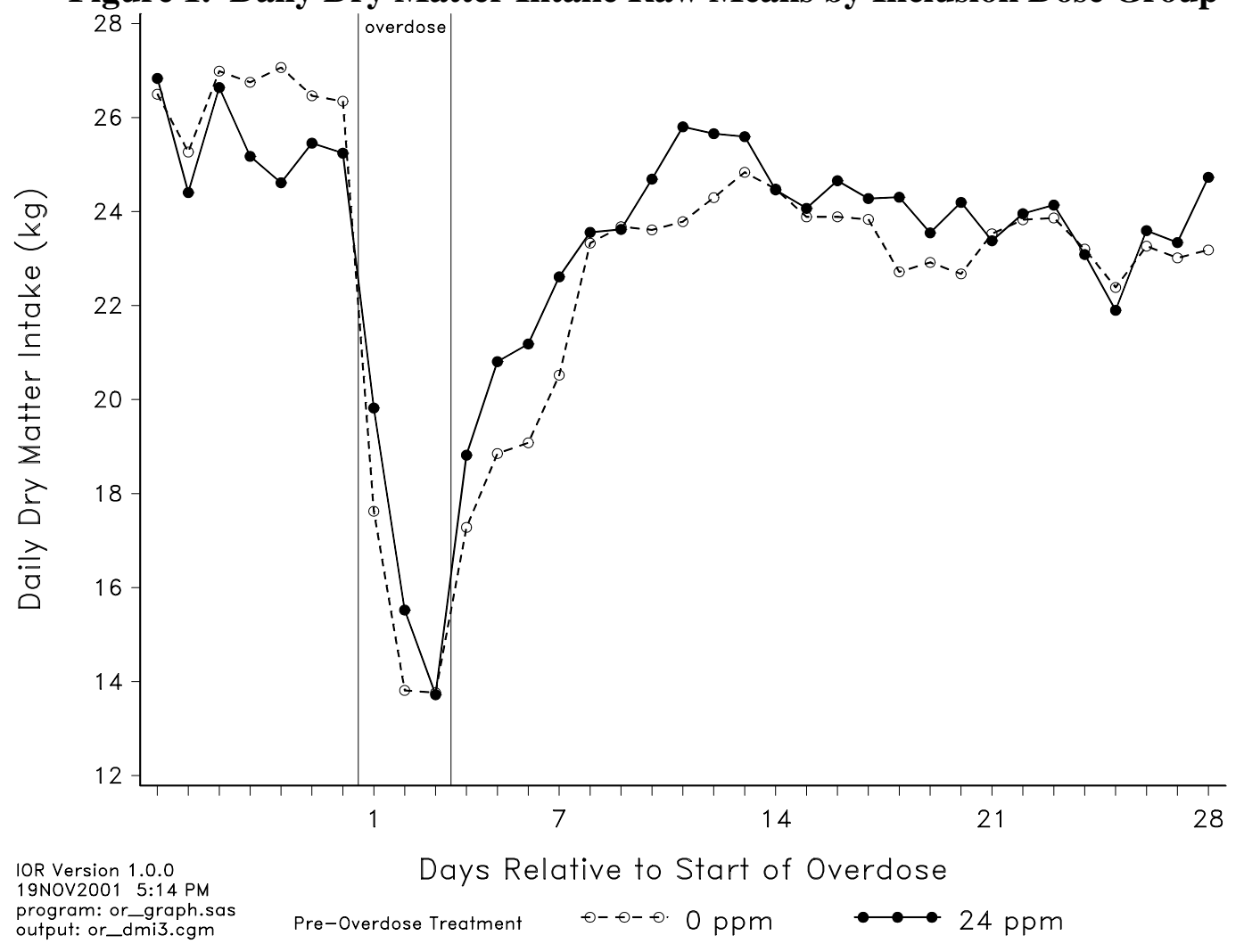


Table 2. Daily Dry Matter Intake (kg/day) Analysis

Overdose Phase

\begin{tabular}{|c|c|c|c|c|c|c|}
\hline Inclus & & & Das & lative & & \\
\hline Dose & & & Star & Overd & & \\
\hline ppm & Stat & Baseline & 1 & 2 & 3 & Average \\
\hline 0 & LSMean & 26.5 & 17.3 & 13.6 & 13.5 & 14.8 \\
\hline 24 & LSMean & 25.5 & 20.1 & 15.8 & 13.9 & 16.6 \\
\hline & P-value & & 0.003 & 0.012 & 0.692 & \\
\hline
\end{tabular}

\begin{tabular}{lr} 
Source & P-value \\
\hline Dose & 0.008 \\
Day & $<0.001$ \\
Dose * Day & 0.108 \\
\hline \hline
\end{tabular}

Dose indicates the Inclusion Dose. 
Table 3. Daily Dry Matter Intake (kg/day) Analysis Acute Recovery Phase

\begin{tabular}{|c|c|c|c|c|c|c|c|c|}
\hline \multicolumn{3}{|c|}{ IDose RDose } & \multicolumn{6}{|c|}{ Day Relative to Start of Overdose } \\
\hline ppm & ppm & Stat & Baseline & 4 & 5 & 6 & 7 & Average \\
\hline 0 & 0 & LSMean & 26.3 & 16.8 & 18.7 & 18.7 & 20.4 & 18.7 \\
\hline 0 & 24 & LSMean & 26.7 & 17.0 & 18.3 & 18.7 & 19.8 & 18.4 \\
\hline 24 & 0 & LSMean & 25.2 & 19.6 & 21.8 & 22.8 & 23.2 & 21.8 \\
\hline 24 & 24 & LSMean & 25.7 & 18.9 & 20.6 & 20.4 & 22.8 & 20.7 \\
\hline & & Main Eft & & & & & & \\
\hline 0 & & LSMean & 26.5 & 16.9 & 18.5 & 18.7 & 20.1 & 18.5 \\
\hline 24 & & LSMean & 25.5 & 19.2 & 21.2 & 21.6 & 23.0 & 21.2 \\
\hline & 0 & LSMean & 25.8 & 18.2 & 20.2 & 20.7 & 21.8 & 20.3 \\
\hline & 24 & $\underline{\text { LSMean }}$ & 26.2 & 17.9 & 19.4 & 19.5 & 21.3 & 19.5 \\
\hline & & Idose P- & & 0.001 & $<0.001$ & $<0.001$ & $<0.001$ & \\
\hline & & Rdose $\mathrm{P}$ & & 0.691 & 0.252 & 0.077 & 0.435 & \\
\hline & & IDose*R & se P-value & 0.535 & 0.582 & 0.089 & 0.939 & \\
\hline
\end{tabular}

\begin{tabular}{lr} 
Analysis of Variance & P-value \\
\hline IDose & $<0.001$ \\
RDose & 0.109 \\
Day & $<0.001$ \\
IDose * RDose & 0.263 \\
IDose * Day & 0.909 \\
RDose * Day & 0.735 \\
IDose * RDose * Day & 0.574 \\
\hline \hline
\end{tabular}

IDose indicates Inclusion Dose.

RDose indicates Recovery Dose. 
Table 4. Daily Dry Matter Intake (kg/day) Analysis

Chronic Recovery Phase

\section{Week}

Relative

to

\begin{tabular}{|c|c|c|c|c|c|c|c|}
\hline \multirow{2}{*}{$\begin{array}{l}\text { IDos } \\
\text { ppm }\end{array}$} & \multirow{2}{*}{$\begin{array}{l}\text { RDose } \\
\text { ppm }\end{array}$} & \multirow{2}{*}{ Stat } & \multirow[b]{2}{*}{ Baseline } & \multicolumn{3}{|c|}{ Start of Overdose } & \\
\hline & & & & 2 & 3 & \multicolumn{2}{|c|}{4 Average } \\
\hline & 0 & LSMean & 26.3 & 23.6 & 22.6 & 22.4 & 22.9 \\
\hline 0 & 24 & LSMean & 26.7 & 23.4 & 23.1 & 23.1 & 23.2 \\
\hline 24 & 0 & LSMean & 25.2 & 25.4 & 25.0 & 24.4 & 24.9 \\
\hline \multirow[t]{2}{*}{24} & 24 & LSMean & 25.7 & 25.0 & 24.1 & 23.6 & 24.3 \\
\hline & & Main Eff & & & & & \\
\hline 0 & & LSMean & 26.5 & 23.5 & 22.8 & 22.7 & 23.0 \\
\hline \multirow[t]{6}{*}{24} & & LSMean & 25.5 & 25.2 & 24.5 & 24.0 & 24.6 \\
\hline & 0 & LSMean & 25.8 & 24.5 & 23.8 & 23.4 & 23.9 \\
\hline & 24 & $\underline{\text { LSMean }}$ & 26.2 & 24.2 & 23.6 & 23.3 & 23.7 \\
\hline & & \multicolumn{2}{|c|}{ Idose P-value } & 0.012 & 0.015 & 0.062 & \\
\hline & & \multicolumn{2}{|c|}{ Rdose P-value } & 0.617 & 0.815 & 0.936 & \\
\hline & & \multicolumn{2}{|c|}{ IDose*Rdose P-value } & 0.912 & 0.292 & 0.293 & \\
\hline
\end{tabular}

\begin{tabular}{lr} 
Analysis of Variance & P-value \\
\hline IDose & 0.009 \\
RDose & 0.727 \\
Week & 0.028 \\
IDose * RDose & 0.349 \\
IDose * Week & 0.768 \\
RDose * Week & 0.927 \\
IDose * RDose * Week & 0.607 \\
\hline \hline
\end{tabular}

IDose indicates Inclusion Dose.

RDose indicates Recovery Dose. 
Table 5. Milk Fat Percent Analysis

Acute Recovery Phase

\begin{tabular}{ccrrrrr} 
IDose & RDose & & \multicolumn{3}{c}{ Overdose } \\
\cline { 5 - 7 } ppm & ppm & Stat & Baseline & $\mathbf{4}$ & $\mathbf{7}$ & Average \\
\hline 0 & 0 & LSMean & 3.64 & 2.65 & 2.02 & 2.33 \\
0 & 24 & LSMean & 3.53 & 2.64 & 2.11 & 2.37 \\
24 & 0 & LSMean & 3.48 & 2.84 & 2.02 & 2.43 \\
24 & 24 & LSMean & 3.34 & 3.33 & 2.42 & 2.88 \\
\cline { 5 - 7 } & Main Effects & & & & \\
0 & & LSMean & 3.58 & 2.64 & 2.07 & 2.35 \\
24 & \multirow{2}{*}{ LSMean } & 3.41 & 3.08 & 2.22 & 2.65 \\
& & & & & \\
& 0 & LSMean & 3.56 & 2.74 & 2.02 & 2.38 \\
& 24 & LSMean & 3.44 & 2.98 & 2.27 & 2.63 \\
\cline { 4 - 7 } & Idose P-value & & 0.002 & 0.251 & \\
& & Rdose P-value & & 0.077 & 0.077 & \\
& & IDose*Rdose P-value & & 0.068 & 0.259 &
\end{tabular}

\begin{tabular}{lr} 
Analysis of Variance & P-value \\
\hline IDose & 0.011 \\
RDose & 0.030 \\
Day & $<0.001$ \\
IDose * RDose & 0.064 \\
IDose * Day & 0.122 \\
RDose * Day & 0.979 \\
IDose * RDose * Day & 0.599 \\
\hline \hline
\end{tabular}

IDose indicates Inclusion Dose.

RDose indicates Recovery Dose. 